\section{The Price of Power: How Firm's Market Power Affects Perceived Fairness of Price Increases}

\author{
Shumaila Zahid ${ }^{1}$, Wisha Nadeem², Hamza Sarwer ${ }^{3}$
}

The Journal of Educational Paradigms 2019, Vol. 01(01) 13-17

(C) Authors

ISSN (Print): 2709-202X

ISSN (Online): 2709-2038

DOI: $10.47609 / 0101022019$



\begin{abstract}
How does? Market power effect the consumer purchase attention and buying behavior? To answer our research question in hypothetically and significant important perspective of price increase, we illustrate that (i) when the price increase is due to cost of goods sold consumer price fairness observation will decay with market power (ii) this fairness issue increase due to greater awareness of controllability of the firms with high market power (iii) when the price increase is not in the control of firms (and in this way saw as similarly reasonable for firms. with high and low market power). In our research above, predictions are empirically supported through quantitative studies of the survey. To address the research problem, we collect the data through convenience sampling from the consumers of Retail outlets. Our findings highlight how firm market power and pricing strategies influence the consumer awareness of price unfairness and the firm's competition in the retail marketplace.
\end{abstract}

Keywords: market power, consumer perception, price fairness, controllability

During the last decade, educational economists have established various approaches using economic methodologies to measure market power. These approaches are based on highlighting the way firms or industry's price and output respond to changes in the economic environment. Thousands of websites ranking the firms/brands market power based on their size and market share. Numouras studies suggest that usually, people believe that selling price often is more than the fair price. Due to different Price increase reasons (cost of goods sold, labor cost, competitors price, etc.), consumer react very sensitively. Still, consumers do not understand the fact of inflation and increase of vendor cost (Lisa E. Bolton, 2009). Perception of price fairness affect the consumer satisfaction (Sinha and Batra, 1999). The literature has given the most attention to PL/NB price competition. Market share plays a significant role in firm market power. In most cases, the National still has the advantage of a price premium, quality innovation, equity, and brand image. Supermarket retailers are creating and promoting store brands, also known as private brands, flourishing day by day, and becoming direct competitors of national brands also affecting pricing decisions (Koen Pauwels, 2009).

In the past, there is not much research available on consumer perception regarding firm market power. This study focuses on the consumer's response to the price increase of the National brand/private label according to their market power. This study aims to see (i) how consumer perception of fairness has arisen in the context of market power when the price increase is due to cueing of goods sold, and labor cost and (ii) will consumers respond differently as a function of firm market power.

First, we conduct quantitative research on market power to see how consumer response to price increase as a role of market power. We will research a private label and national brand price competition according to their market power.
Second, we examine the market power effect on the consumer reaction to price increase due to cueing cost of goods sold and labor cost. This question is crucial for the retailer with high labor. As far as anyone is concerned, earlier research has not inspected the effect of firm market power on customer cost reaction-a hypothetical hole tended to by the current study. In doing as such, we additionally expand on earlier research on customer impression of controllability (Vaidyanathan and Aggarwal, 2003) to reveal insight into the hidden psychological component and distinguish why and when differences in fairness will rise as a capacity of firm market power.

Tending to these holes in the writing has significant consequences for the generalizability of the rule of dual entitlement, just as a more extensive comprehension of market power in a retail setting. From a practical point of view, the current research recognizes an unexamined advantage for firms of lower advertising power, (for example, private marks) and reveals why and when such a favorable position exists. Doing so conveys critical implications for retail and showcasing administrators, given customers' malevolence toward cost builds, the ramifications of estimating for an association's benefit, and rivalry among brands in the commercial retail center.

\section{Literature Review}

\section{Market Power}

Previous research typically focused on consumer power when talk about examining the role of power (Galinsky,2015; Jiang et al., 2014; Rucker et al., 2012). In contrast, recent studies mostly focus on market power, which is determined by its position in the market and, later, reflected in its market share (Baker et al., 1992; Makhija 2003; Shervani et al., 2007; Shamsie 2003). This treatment of market power is consistent with the broader literature that generally views power as asymmetric control over valued

${ }^{123}$ UCP Business School, Faculity of Management Sciences, UCP, Lahore. Corresponding author: $11 \mathrm{f} 19 \mathrm{msba0016@ucp.edu.pk}$ 
resources (Depret and Fiske 1993; Fiske 2010; Keltner, Gruenfeld, and Anderson 2003; Magee and Galinsky 2008; Thibaut and Kelley 1959). When we talk about market power in the marketing context, it is defined as an organization's ability to influence others' actions in inter-firm relationships or product market (Kim et al., 2004; Makhija 2003; Shervani et al., 2007; Porter 2008;). Here, our focus is on how market power affects the customer's response to the price increase. Although market power and firm behavior have recently received considerable attention in economics and marketing, we will still have less focus on examining how market effects consumer behavior (Boulding and Staelin 1990; Porter 2008; Shamsie 2003). There can be two effects of this; a positive halo effect and a negative halo effect.

On the one hand, when the organizations raise prices and have higher market power, consumers might react favorably because market power confers control over valuable resources and could, therefore, imply greater competence in delivering quality product offerings (Davidson and Neu 1993; Nevo 2001). On the other side, the consumer can have uncertain views about the big corporations arises from the negative opinions about the organizations that can be worsened by high market power (Bhattacharjee, Dana, and Baron 2017; Lam 2014). This research proposes a fairness account and predicts that market power will interact with reasons for a price increase to drive consumers' price fairness perceptions and, in turn, consumer purchase behavior to these competing predictions.

Table 1: Outlines the Definition of Main Constructs

\begin{tabular}{ll}
\hline Constructs & \multicolumn{1}{c}{ Definition } \\
\hline Market Power & $\begin{array}{l}\text { An organization's ability to influence the } \\
\text { actions of others in inter-firm relationships } \\
\text { or product market (Kim et al., 2004; } \\
\text { Makhija 2003; Shervani et al., 2007; Porter, } \\
\text { 2008) }\end{array}$
\end{tabular}

Price Fairness The definition of fairness is a process or outcome of judgment to reach an outcome that is reasonably acceptable or just (Bolton et al., 2003; Campbell 1999; Chen et al. 2018; Xia, Monroe, and Cox 2004).

Controllability Defined as an action that is under the volitional control of an actor or not (Folkes 1988; Vaidyanathan et al., 2003)

Price Fairness as a Function of Market Power Price Fairness The definition of fairness is a process or outcome of judgment to reach a reasonably acceptable or justifiable issue (Bolton et al., 2003; Campbell 1999; Chen et al. 2018; Xia, Monroe, and Cox 2004). Buyer's and seller's judgment regarding price fairness influence the actual purchases, behavioral intentions, and satisfaction of both (Bolton et al., 2010; Finkel 2001; Heyman et al. 2008; Haws et al., 2006; Sinha et al., 1999).

According to Kahneman et al., (1986), In the existing literature, researchers emphasize that dual power influences price fairness judgment. Dual control is something when organizations are keen to profit, whereas; customers are entitled to reference points. According to this principle, consumers judge it fair when firms increase prices due to costs (because doing so protects firms' entitlement to their reference profit). However, unfair when firms increase rates to take advantage of demand (because doing so violates consumers' right to reference price). Building upon this early research, we develop arguments that increase in price and market power jointly determine consumers' fairness perception and, in turn, purchase behavior.

\section{Price increase due to costs}

Power deliberate to those who have more a cost will increase when the consumers observe that companies with high market power have more control in setting the prices (Anderson and Galinsky 2006; Keltner, Gruenfeld, and Anderson 2003; Magee and Galinsky 2008; Galinsky et al. 2008). There are two types of power holders; high powerholders are assumed to act freely, while; having fewer constraints. Whereas on the other hand, low power holders face more obstacles while having less freedom (Fast et al. 2009; Galinsky et al., 2003; Inesi et al. 2011; Jiang et al. 2014; Overbeck et al., 2006). Therefore, firms with high market power are assumed to have more control over their costs constraints and decisions while on the other hand, firms have less control over cost constraints and increase their prices with low market power.

According to both Folkes (1988); Vaidyanathan et al., (2003), Controllability is considered an important attribute that consumers made. It is viewed as an action that is under the voluntary control of an actor or not. Same with the case with the firm response that is relatively different depends on perceived Controllability. Based on this, we hypothesize that high power firms perceive increased prices as controllable. Consumers will assume an increase in price as less fair when firms with high (vs. low) market power pass on cost increases to customers.

\section{Price increase due to Labor}

According to Peneva and Rudd (2017), the relationship between labor cost and price weakened over time, the increase in the cost of labor perceived to have an impact on the increased rate in the short run. Studies here tend to find that, while in the past (i.e., and Brion the mid-1980s), labor cost inflation did provide signals for the price increase. There is little evidence that in recent years movements in average labor cost growth have been a significant independent influence on price increased. According to Knotek and Zaman (2014), an increase in labor costs does not provide signals to the rise in price in recent years. Labor cost inflation has less effect on price increased. The firm with high market power has less impact on perceived labor cost inflation. Similarly, Peneva and Rudd (2017) show how the pass-through of labor cost growth to price inflation has declined over the past several decades (to the point where it is currently close to zero). Labor markets have been a focus of interest in the study of price inflation. Based on this theorizing, we make the following hypothesis;

H1. Consumer price fairness perceptions and purchase intentions will be lower for firms with high (vs. low) market power when a price increase is due to cueing cost of goods sold and labor cost

H2: Differences due to market power as postulated in $\mathrm{H}_{1}$ arise because consumers perceive greater controllability

\section{Methodology Sample and Procedure}

We structure and led a multi-source survey to test our Hypothesis. We plan a study organized to gather the information from Carrefour consumer's. Carrefour is managing diverse national and private label brands of Mango Juice. Our structured questionnaire has three parts (i) Price Fairness as a Function of Market Power 
NB/PL (ii) Price Fairness as a Role of Market Power (iii) Market power and Controllability.

In this study, we focus on price increases in the Mango juice category during a well-known episode of a cost increase caused by the Pandemic of COVID-19 and Bat attack on Mango trees in 2020. Mango season was hugely affected because of these two reasons, and suppliers suddenly increase the price of Mangoes. Due to changes in the cost, prices respond very quickly and almost change instantly (Dutta, Bergen, and Levy, 2002). A short supply of Mangoes causes a sudden increase in cost and price as well. This news flash on every news channel. That's why customers know why the shortage of Mango and the rise of Mango juice prices.

To test our Hypothesis, we take 640z. Refrigerated Mango juice because it is the most popular size of Mango juice and its sale high as compare to other sizes. We consider three national brands (Nesfruita, Fruita Vitals, and Slice) with high market power, and one private brand (Welch's) with small market share.

\section{Price Fairness as a Function of Market Power (NB/PL)}

Members were requested to rate value reasonableness observations on five-point (Strongly disagree, Disagree, Neutral, Agree, and Strongly Agree). A short time later, members evaluated their impression of abuse: "The brand is exploiting its clients," "The brand is misusing clients", "The brand isn't doing anything incorrectly to its clients, "Clients are not being treated with the regard they are expected," "The brand is harming its clients," and "Clients are encountering hurt because of the decisive moves"' Participants likewise demonstrated their value premium discernments on a five-point scale (Strongly disagree, Disagree, Neutral, Agree, Strongly Agree): "National brands are commonly more costly than private names." Finally, members responded to segment questions.

\section{Fairness as a Function of Market Power (Market Share)}

The principle goal is to test $\mathrm{H} 1$ and $\mathrm{H} 2$ with immediate control of market power through a piece of the overall industry. In this part, Participants were then approached to rate purchase goals, price awareness. As a control check, members likewise evaluated their impression of market power on five-point scales "strongly disagree/strongly agree." The market share of the brand is very large/small.

\section{Firm Market Power and Controllability}

This part analyzes a cost-based cost increment for a high and low market power firm and thinks about decency observations when the cost increment is controlled as past the association's control or not. Reliable with $\mathrm{H} 1$ and $\mathrm{H} 2$, a cost-based cost increment (of unknown controllability) will be seen as less reasonable for the high versus low market power firm. Because of the impression of more outstanding controllability and misuse.

Conversely, a cost-based cost increment that is past the association's control will be judged moderately reasonable, paying little mind to firm power (i.e., market power $\rightarrow$ controllability $\rightarrow$ unfairness.

Members evaluated the controllability of the store's choice to change cost on three six-point scales (with end focuses

"unavoidable/avoidable," "past/inside their control," and "the store had no other/a ton of different decisions"). For firm force, members evaluated the firm on four six-point scales (with endpoints "little/huge." Data Collection

Fifty customers of Carrefour filled questionnaires who are a regular user of Mango juice. Questionnaire consist of three major parts. Each question has 5 point liker scale (Strongly disagree, Disagree, Neutral, Agree, Strongly Agree). The response rate of the questionnaire is $60 \%$. The respondents' age lies between $20-30$ and $80 \%$, and the remaining $20 \%$ belong to other age groups. $27 \%$ of respondents have a bachelor's degree, $46 \%$ have MPhil/MBA degrees, and remaining have different education degrees. $26 \%$ of respondents have income between 15-30 thousand PKR, and 40\% have 50 thousand and above salary. Question about favorite mango juice between three national brands and one private label is also asked the respondents.48\% choose Nesfruita, 34\% select Vitals Fruita, and the remaining $18 \%$ want Mango Slice. Nobody will go with a private brand.



Figure 1: Conceptual Framework

\section{Results Regression Analysis}

We use two models to test the hypotheses. We analyze our data by using regression that is proposed at the start. In model one analysis that is a statistical use or technique, we test our first hypotheses by using to test the hypotheses. The table shows the different regression analysis of the correlation between the results of the variables, and the results demonstrated that the price increase reason using regression analysis. Table 1 describes the (Moderator) as having a positive effect on the demographic education and the income of the dependent variable (Behavior Intention) and respondents. Table 2 describe the independent variable (Market Power) the correlation between the variables and the beta value 0.455 and significance value is table 3 shows the results of our hypotheses. 0.00, so our first hypotheses are supported. In Correlation Analysis, the second model, we test our second hypothesis that the controllability table 2 shows the correlation of the variable.

(Mediator) of brands has a positive impact

Table 2 shows that there is a positive on the dependent (Behavior Intention) and the relation between the dependent variable, the independent variable (Market Power) we (Behavior intention), and independent used the Process Micro by Andrew F. Hayes variable (Market Power). The R-square to check the mediator's effect on the value is 0.67 , which means that the relation of a dependent and independent variable defines the dependent variable. We conclude that the mediator has a variable by $67 \%$. The remaining variable, like the positive effect on the relation between controllability, is a mediator and price. The dependent and independent variable increase reason is moderator has also the their Beta value is 0.346, and the p-value is 0.000 effect between the relation of dependent and independent variable, which shows that our second hypothesis is also supported. 
Table 2: Descriptive Statistics

\begin{tabular}{lccc}
\hline Variables & $\begin{array}{c}\text { Standard } \\
\text { deviation }\end{array}$ & Mean & Median \\
\hline Behavior Intention & 0.97 & 3.1364 & 3.0000 \\
Market Power & 0.91 & 3.1111 & 3.3333 \\
Controllability & 0.92 & 3.3955 & 3.5833 \\
Price increase reasons & 0.92 & 3.3955 & 3.0000 \\
\hline
\end{tabular}

Table 3: Regression Analysis

\begin{tabular}{ccccccc}
\hline No & Hypothesis & Beta & SE & $\begin{array}{l}\text { t- } \\
\text { value }\end{array}$ & $\begin{array}{l}\text { P- } \\
\text { value }\end{array}$ & Decision \\
\hline 1 & PIR & $0.455^{* * * *}$ & 0.151 & 3.022 & 0.000 & Supported \\
& BI->MP & & & & & \\
2 & C & $0.346^{* * *}$ & 0.037 & 9.386 & 0.000 & Supported \\
& BI->MP & & & & & \\
& & & & & &
\end{tabular}

*p<.10; ** $\mathrm{p}<.05 ; * * * \mathrm{p}<.001$. Price Increase reason (PIR), (BI), Behavior Intention (BP), Market Power (MP) and Controllability (C).

General Discussion

How does market power influence the consumer purchase attention and buying behavior? To answer our research questions in the theoretical context of the price increase. We theorize that (i) when the price increase is due to the cost of goods sold, consumer price fairness observation will decay with market power. (ii) This fairness issue increase due to greater awareness of the controllability of the firms with high market power. (iii) when the price increase is not in the control of firms (and in this way saw as similarly reasonable for firms with high and low market power). In our research above, predictions are empirically supported through quantitative studies of the survey. To address the research problem, we collect the data through convenience sampling from the consumers of Retail outlets. Our findings highlight how firm market power and pricing strategies influence the consumer awareness of price unfairness and the firm's competition in the retail market place.

\section{Theoretical Contribution \\ Market Power}

This research has a significant contribution in literature for both practitioners and retailers on market power in different ways. In the previous research, they mostly focus on the pricing strategies (price increase due to demand and unspecified). No research is available on consumer response to price increase due to cueing cost of goods sold and labor cost and consumer response to market power.( Paharia, Avery, and Keinan, 2014; Yang and Aggarwal, 2019).

Our research finds that consumers consider it unfair to increase the due price increase in the cost, especially brands with high market power, and change their purchase intention to address this gap.

In our research, we also see the competition among private labels. National brands and research findings show that private labels are far behind the national brand in the context of competition (Nielsen Company, 2018; Sethuraman and Gielens, 2014). In previous research, it is evident that national brands have several advantages over private labels in the shape of innovation, quality, brand image, and equity, which give them the leverage of price premium (Nielsen Company, 2018; Sethuraman and Gielens, 2014). So there is always price asymmetry between private labels and national brands. Our research shows that if a private brand increases its price due to cost, it does not affect the consumer perception and buying behavior.

\section{Price Fairness}

Previous research has explored so many factors of price fairness perception, but it does not examine how market power affects consumer fairness perception. During the investigation, we find a vital factor consumer endorsement of dual entitlement as a community standard of fairness (Kahneman, Knetsch, and Thaler, 1986a, 1986) holds to a lesser extent when firm's market power is higher.

Second, our research reveals the hidden psychological mechanism, recognizing why and when market power contrasts in fairness will rise. According to the current study, controllability is the key: if the price increase is not in the control of firm fairness difference due to market power reduced. In the past, research controllability linked to fairness awareness, and we add price increase reason as moderator. Fairness awareness provides a new way for consumers to understand the marketplace and downstream results of purchase intention. Managerial Implication

The current research result suggests that firms with high market power are more affected by price increase than firms with low market power. This will also give a competitive disadvantage to the national brand. Among the most important activities for supermarket, retailers is the creation and marketing of store brands, also known as private label brands. Given the increasing quality-equivalence between national brands and store brands, they have become direct competitors, and pricing decisions should take this into account (K. Pauwels and S.Srinivasan, 2004).

Second, it suggests that if the firm conveys to customers that price increase is beyond their control, they will reduce the perception of unfairness. Small retailers will communicate it quickly, but for large retailers and manufacturers, it is challenging. Sometimes, it works very adversely like Netflix will convey it to customers and lose their 30,000 subscribers because consumers think cost and price increase are in the control of National brands.

Third, we suggest that firms and retailers be susceptible to consumer perception of the price increase, and they will face backlash from the consumers due to changes over time (Kumar and Steenkamp, 2007; Nielsen, 2018).

\section{Limitations and Future Research}

Our research is not without limitations. We built pioneering research on market power's effect on price fairness perception. Still, there is also a vast field available to work on the related literature, and further work will be precious.

Our research is not providing a generalizability claim. Future exploration that inspects other valuing settings, just as qualities of buyers and firms, is justified. Given a retailing context, the accompanying lines of inquiry strike us as promising. 
Previous research mostly focuses on the reason for price increase due to increment of cost, but future research could be conducted on the cost decrease and how it will affect the price.

Future research could also conduct the cross-culture differences and see the impact of market power on consumer behavior intention regarding price. Consumers respond very differently in independent and interdependent cultures.

In conclusion, we can say that firms with high market power may enjoy price premiums and other advantages. Still, it will also come with a price tag of consumer perception of unfairness and exploitation.

\section{References}

Anderson, Cameron and Adam D. Galinsky (2006). Power, optimism, and risk-taking. European Journal of Social Psychology, 36, 511-36.

Baker, J. B. (1992). J. \& T. Bresnahan,-Empirical Methods of Identifying and Measuring Market Powerll. Antitrust Law Journal, 61, 3-16.

Bhattacharjee, A., Dana, J., \& Baron, J. (2017). Anti-profit beliefs: How people neglect the societal benefits of profit. Journal of personality and social psychology, 113(5), 671.

Bodur, H. O., Klein, N. M., \& Arora, N. (2015). Online price search: Impact of price comparison sites on offline price evaluations. Journal of Retailing, 91(1), 125-139.

Bolton, L. E., \& Alba, J. W. (2006). Price fairness: Good and service differences and the role of vendor costs. Journal of Consumer Research, 33(2), 258-265.

Bolton, L. E., Keh, H. T., \& Alba, J. W. (2010). How do price fairness perceptions differ across culture?. Journal of Marketing Research, 47(3), 564-576.

Dutta, S., Bergen, M., \& Levy, D. (2002). Price flexibility in channels of distribution: Evidence from scanner data. Journal of Economic Dynamics and Control, 26(11), 1845-1900.
Fast, N. J., Gruenfeld, D. H., Sivanathan, N., \& Galinsky, A. D. (2009). Illusory control: A generative force behind power's farreaching effects. Psychological Science, 20(4), 502-508.

Finkel, N. J. (2001). Not fair!: The typology of commonsense unfairness. American Psychological Association.

Fiske, Susan T. (2010). Interpersonal stratification: Status, power, and subordination, in Handbook of social psychology, Fiske Susan T., Gilbert Daniel T. and Lindzey Gardner, eds. NJ: Wiley, 941-82.

Folkes, V. S. (1988). Recent attribution research in consumer behavior: A review and new directions. Journal of consumer research, 14(4), 548-565.

Kumar, N. (2007). Private label strategy: How to meet the store brand challenge. Harvard Business Review Press.

Nielsen Company (2018). The Rise and Rise Again of Private Label, February 28.

Paharia, N., Avery, J., \& Keinan, A. (2014). Positioning brands against large competitors to increase sales. Journal of Marketing Research, 51(6), 647-656.

Sethuraman, R., \& Gielens, K. (2014). Determinants of store brand share. Journal of Retailing, 90(2), 141-153.

Sinha, I., \& Batra, R. (1999). The effect of consumer price consciousness on private label purchase. International journal of research in marketing, 16(3), 237-251.

Vaidyanathan, R., \& Aggarwal, P. (2003). Who is the fairest of them all? An attributional approach to price fairness perceptions. Journal of Business Research, 56(6), 453-463.

Yang, L. W., \& Aggarwal, P. (2019). No small matter: how company size affects consumer expectations and evaluations. Journal of Consumer Research, 45(6), 1369-1384. 